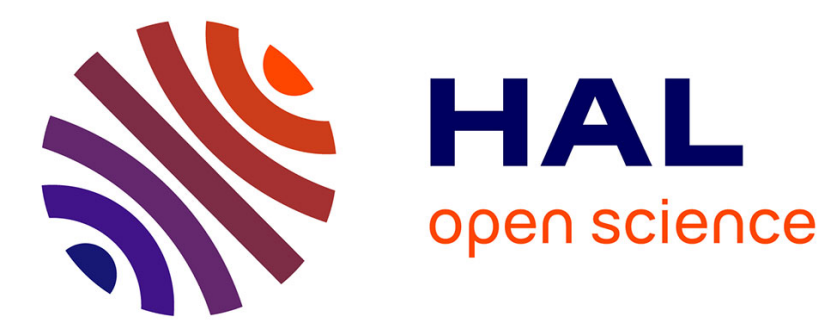

\title{
Effect of two diffuser types of volute on pressure fluctuation in centrifugal pump under part-load condition
}

Fan Meng, Ji Pei, Shouqi Yuan, Yin Luo, Jia Chen

\section{To cite this version:}

Fan Meng, Ji Pei, Shouqi Yuan, Yin Luo, Jia Chen. Effect of two diffuser types of volute on pressure fluctuation in centrifugal pump under part-load condition. 16th International Symposium on Transport Phenomena and Dynamics of Rotating Machinery, Apr 2016, Honolulu, United States. hal-01891318

\author{
HAL Id: hal-01891318 \\ https://hal.science/hal-01891318
}

Submitted on 9 Oct 2018

HAL is a multi-disciplinary open access archive for the deposit and dissemination of scientific research documents, whether they are published or not. The documents may come from teaching and research institutions in France or abroad, or from public or private research centers.
L'archive ouverte pluridisciplinaire HAL, est destinée au dépôt et à la diffusion de documents scientifiques de niveau recherche, publiés ou non, émanant des établissements d'enseignement et de recherche français ou étrangers, des laboratoires publics ou privés. 


\title{
EFFECT OF TWO DIFFUSER TYPES OF VOLUTE ON PRESSURE FLUCTUATION IN CENTRIFUGAL PUMP UNDER PART-LOAD CONDITION
}

\author{
Fan Meng, Ji Pei, Shouqi Yuan, Yin Luo, Jia Chen
}

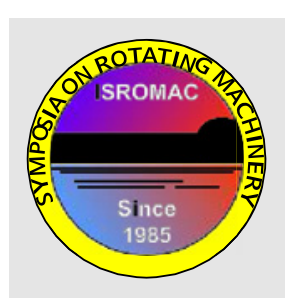

ISROMAC 2016

International

Symposium on Transport

Phenomena and Dynamics of

Rotating Machinery

Hawaii, Honolulu

April 10-15, 2016

\section{Abstract}

In order to adapt various installation positions of pipeline, the volute of centrifugal pump needs to be designed into different types, the volute with tangential diffuser and the volute with radial diffuser. Generally speaking, different diffuser types of volute will affect the performance of pump, while in this paper, little effect can be found. In addition, different diffuser types of volute have a strong influence on flow characteristic in pump and piping system. Especially under part-load condition, pressure fluctuation will be affected more obviously. Two diffuser types of volute were designed to study the effect on pressure fluctuation features of centrifugal pump under part-load condition, with the same volute design parameters and impeller parameters. The unsteady, three dimensional turbulent flow in the pump was simulated by using ANSYS CFX 14.5 in this paper. Then the distribution of pressure fluctuation intensity in the centrifugal pump is achieved and analyzed comparatively under part-load condition. It shows that the periodic features in pressure fluctuation near its tongue are the same for two diffuser types of volute, however in the diffuser of the volute, the values of the pressure fluctuation in radial diffuser is greater than that in tangential diffuser. The results can provide a useful reference for designing the diffuser of volute in centrifugal pump.

\section{Keywords}

Part-load condition - Tangential diffuser — Radial diffuser — Pressure fluctuation

Nation Research Centre of Pumps, Jiangsu University Zhenjiang, Jiangsu, China

Fan Meng: 798836232@qq.com

\section{INTRODUCTION}

Centrifugal pump has two important flow components that are impeller and volute casing basically which together determine the centrifugal pump performance. As an important flow components within a centrifugal pump, volute casing plays an important role of diversion and rise pressure. In order to adapt various installation positions of pipeline, the volute of centrifugal pump needs to be designed into different types.

With the development of computational algorithms and computer technology, the application of CFD (computational fluid dynamics) is becoming more and more popular for studying the pressure fluctuation in pumps.

The pressure fluctuation in centrifugal pump has been studied by many researchers. Glc $\mathrm{M}$ et al ${ }^{[1]}$ and Kergourlay et al [2] studied the effect of blade on pump performance and flow field. Wang Wenquan et al ${ }^{[3]}$ and Germano $\mathrm{M}^{[4]}$ investigated the Large-eddy simulation of turbulent flow numerical computation. Longatte $\mathrm{F}$ et al ${ }^{[5]}$ search the rotor-stator-circuit interactions in a centrifugal pump. Other researchers reported the numerical simulation on pressure fluctuations such as the work by Kitano Majidi et al [6], Guo Pengcheng et al ${ }^{[7]}$ and Zhu Lei et al ${ }^{[8]}$. However, few researchers study the effect of different diffuser types of volute on pressure fluctuation.

In this study, two diffuser types of volute were designed to study the effect on pressure fluctuation features of centrifugal pump under part-load condition, with the same volute design parameters and impeller parameters.

\section{NUMERICAL SIMULATION}

\section{1 Geometry of the pump}

The model pump consists of the impeller, suction and volute. The main geometry parameters of the impeller and the volute are shown in Table 1. Two diffuser types of volute are designed. The first one is the tangential diffuser type of volute, the second one is the radial diffuser type of volute, and the volute design parameters and impeller parameters is the same. The models of impeller and two diffuser types of volute are shown in Figure 1. The impeller is shrouded with 6 twist and backswept blades, with a specific speed of $n_{s}=3.65 n Q^{0.5} / H^{0.75}=162.3$. The main design parameters of the pump for: rotation speed $\mathrm{n}=2900 \mathrm{rpm}$, design flow $Q_{D E S}=330 \mathrm{~m}^{3} / \mathrm{h}$, and design head $\mathrm{H}_{\mathrm{DES}}=48 \mathrm{~m}$.

TABLE 1 THE MAIN GEOMETRICAL AND DESIGN PARAMETERS OF THE RADIAL CENTRIFUGAL PUMP

\begin{tabular}{cccc}
\hline impeller & value & Volute & value \\
\hline$D_{\mathrm{j}} / \mathrm{mm}$ & 135 & $D_{3} / \mathrm{mm}$ & 235 \\
$D_{2} / \mathrm{mm}$ & 225 & $b_{3} / \mathrm{mm}$ & 55 \\
$b_{2} / \mathrm{mm}$ & 32.5 & & \\
$\varphi^{\circ}$ & 120 & & \\
$\beta_{2} /{ }^{\circ}$ & 34 & & \\
$Z$ & 6 & & \\
\hline
\end{tabular}



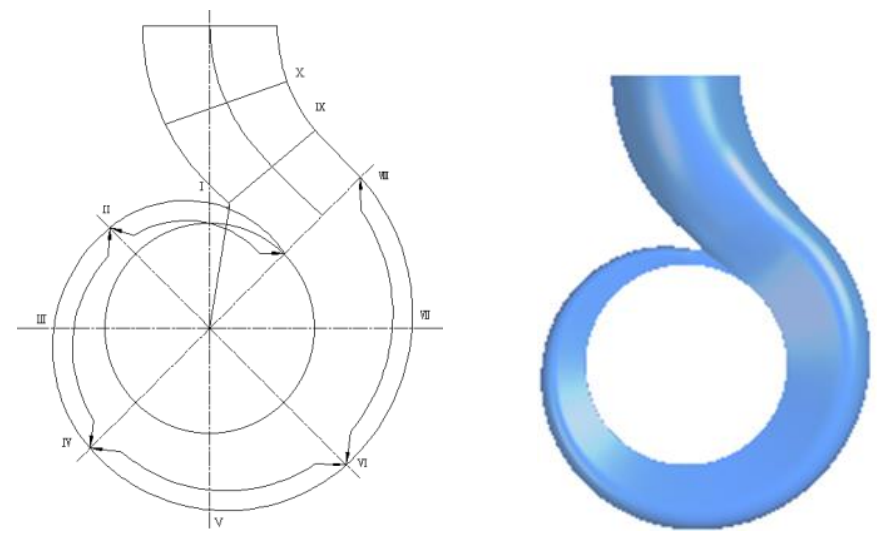

(A) The volute with radial diffuser
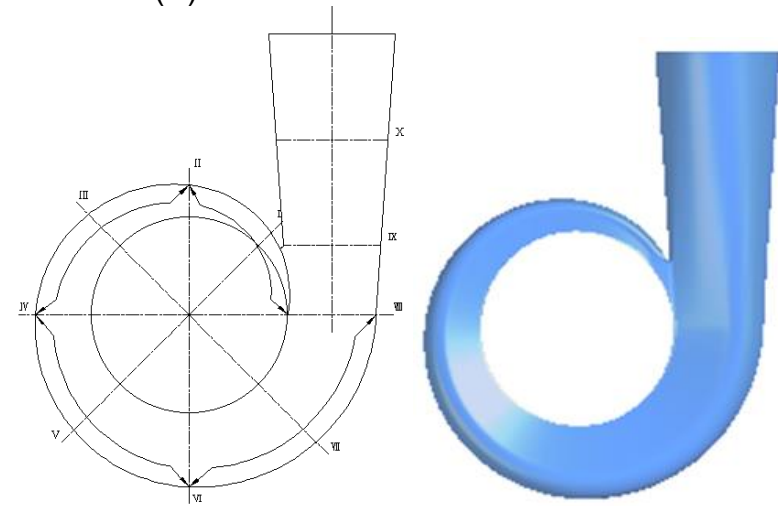

(B) The volute with tangential diffuser

FIGURE 1 The model of impeller and volute with two diffuser types

\subsection{Mesh setup and Turbulence model}

The whole computational domain is made up of the suction, impeller and volute. Computational domains are created by using the grid generation tool ANSYS ICEMCFD, and the mesh is refined in the walls of the channels. The number of mesh is 2630149 and the details of the mesh are shown in Figure 2.

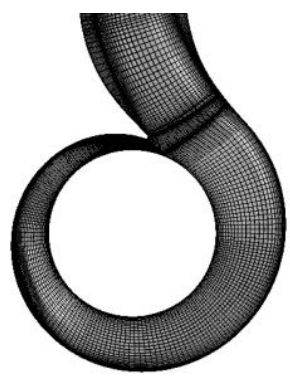

(A) Radial diffuser

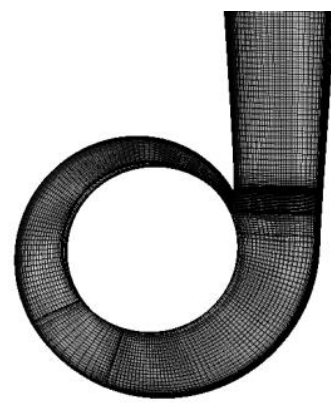

(B) Tangential diffuser

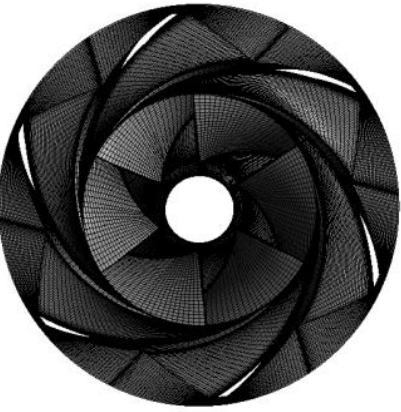

(C) Impeller

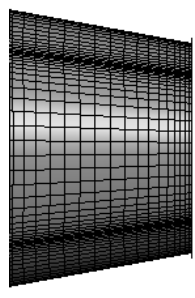

(D) Suction
FIGURE 2 Computational mesh for two diffuser types of volute

Several turbulence models are available in CFX, some have very specific applications while others can be applied to a wider class of flows with a reasonable degree of confidence. However, choosing an appropriate turbulence model for a CFD simulation in a pump is always a challenge. In this study, three-dimensional unsteady simulations were conducted by solving the RANS equations in the design procedure with shear stress transport (SST) k- $\omega$ turbulence model.

\subsection{Boundary conditions}

The interfaces between rotor and stator are set as 'Transient Rotor Stator', while the interfaces between the stator and the stator are set as 'None'. The simulation cycle is set as 6 with 2 degree per time step. Monitoring data of the sixth cycle are analyzed. The total pressure is used in the inlet and the flow direction is normal to the boundary. The mass flow rate is specified in the outlet. All solid walls are no slip and the wall is set as smooth wall in the physical surfaces of the volute, impeller and suction. The high resolution algorithm is employed to solve the equations. The maximum residuals are set to $10-5$, and the values of head, efficiency and power are monitored.

In this paper, the numerical analysis will be done under the part-load condition, $Q / Q_{D E S}=0.8$. To study pressure fluctuation in the centrifugal pump for two diffuser types of volute, the point $c 1$ are set near the tongue and the point $\mathrm{c} 2$ are set in the diffuser. The position of monitor points will be shown in figure 3 . 

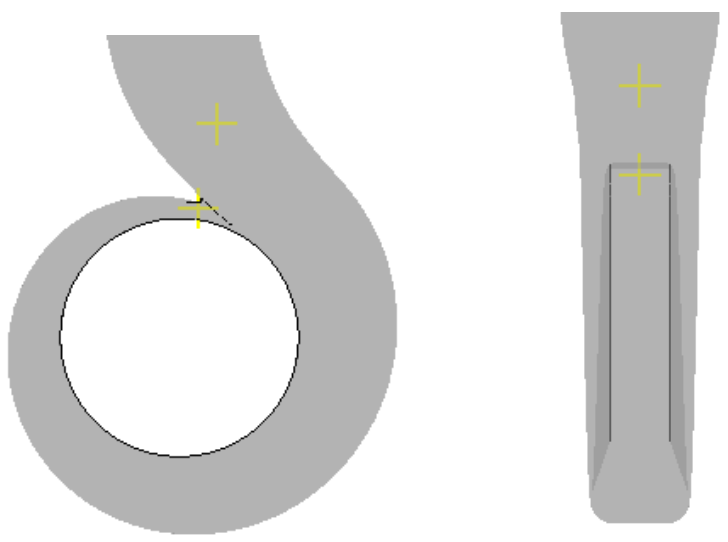

(A) The volute with radial diffuser

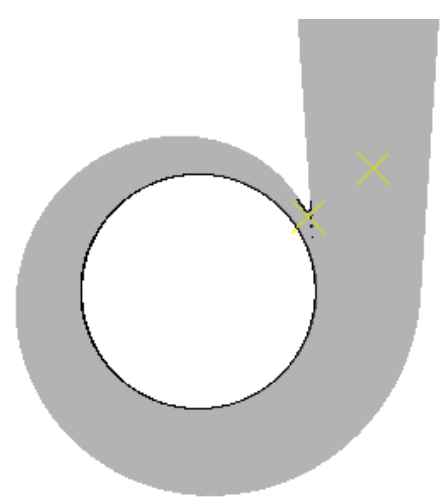

(B) The volute with tangential diffuser

FIGURE 3 The location of monitor point

\section{RESULTS AND DISCUSSION}

\subsection{Comparison of performance}

By using the numerical simulations under 3 different flow rates, the predicted pump performance was obtained for two diffuser types of volute, the volute with radial diffuser and the volute with tangential diffuser. As shown in Figure 4(A). The calculation of each operating point value is the average head and efficiency of a period under unsteady numerical simulation.

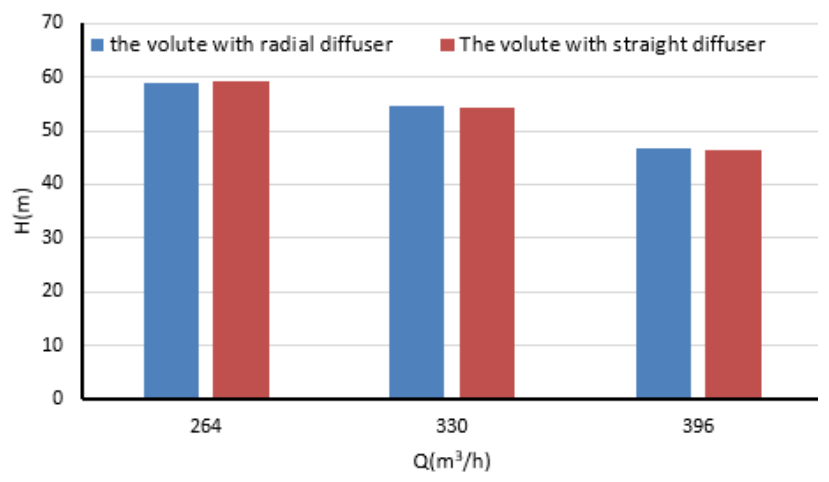

(A) Comparison of the efficiency

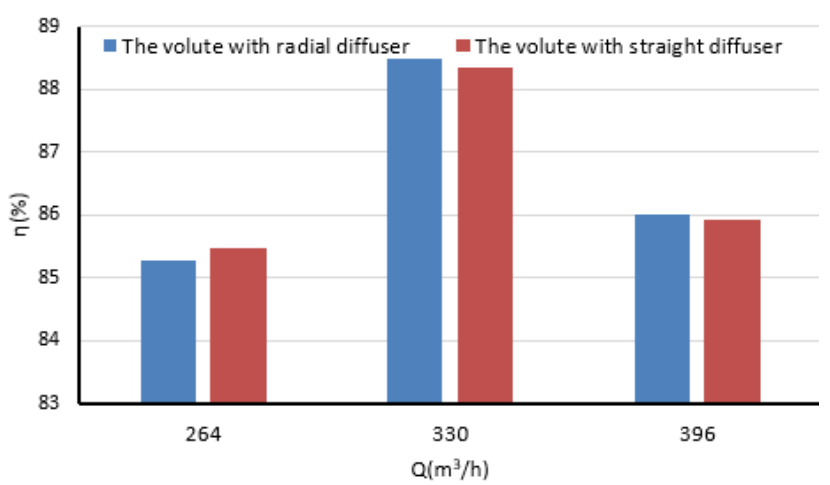

(B) Comparison of the efficiency

FIGURE 4 Comparison of performance for two diffuser types of volute

As shown in the Figure 4, the values of head in the volute with radial diffuser and tangential diffuser decrease gradually with the increase of flow rate. In the volute with radial diffuser, the maximum head value is $59.04 \mathrm{~m}$, and the minimum head value is $46.57 \mathrm{~m}$. In the volute with tangential diffuser, the maximum head value is $59.18 \mathrm{~m}$, and the minimum head value is $46.52 \mathrm{~m}$.

In the two diffuser types of volute, the efficiency value under part-load condition have the biggest difference and that are almost same under other condition. Therefore, it is necessary and significant to study the pressure fluctuation characteristics under part-load condition.

\subsection{Pressure fluctuation intensity distribution}

According to the solution of the turbulence model, the phase average values were obtained for each node, without considering the randomness of instantaneous pressure fluctuation. Because the instantaneous pressure fluctuation has less influence, compared with the phase average value. Using

statistical analysis method to define the pressure fluctuation intensity can guarantee the analysis of the phenomenon on internal flow more accurate and comprehensive. We define the pressure at a node of a period time in the grid is $p(x, y, z, t)$, the pressure is converted into dimensionless pressure fluctuation coefficient:

$$
C_{p}=\frac{P}{0.5 \rho u_{2}^{2}}
$$

Where $\mathrm{u}_{2}$ is the circular velocity at impeller outlet, $P$ is the fluid density. If the impeller rotation cycle is $T$, then the average pressure coefficient value in a period and pressure fluctuation intensity can be shown as the following formula 
cited by Ji Pei (13):

$$
\begin{gathered}
\overline{C_{p}}=\frac{1}{N} \sum_{n=1}^{N} C_{p}\left(x, y, z, \frac{n}{360} T\right) \\
C_{p}^{*}=\sqrt{\left[\frac{1}{N} \sum_{n=1}^{N} C_{p}\left(x, y, z, \frac{n}{360} T\right)-\overline{C_{p}}\right]^{2}} \\
N=360
\end{gathered}
$$

Under part-load conditions, two cross section of fluid channel were created respectively in the diffuser and near the tongue of volute with two diffuser types, as shown in Figure5.

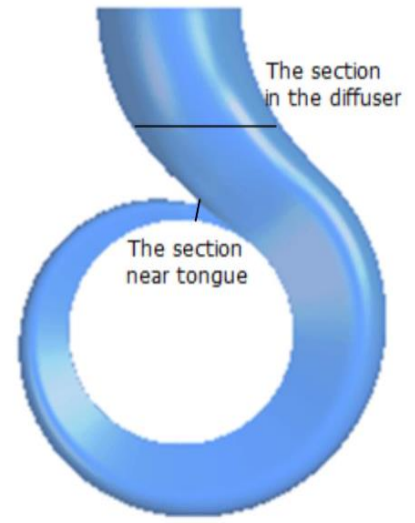

(A) Radial diffuser

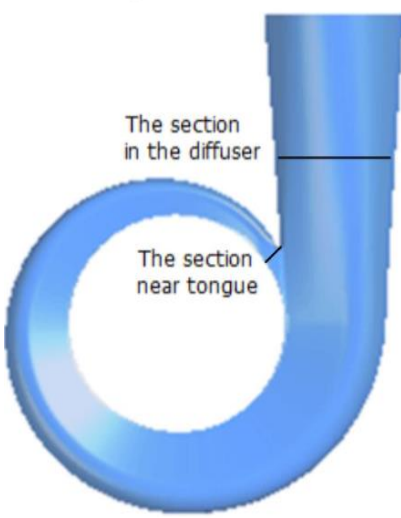

(B) Tangential diffuser

FIGURE 5 The cross section of two diffuser types of volute

The distribution of pressure fluctuation intensity in two diffuser types of volute under part-load condition are shown in Figure 6 and Figure 7.

$$
\begin{array}{r}
6.956 \mathrm{e}-003 \\
6.830 \mathrm{e}-003 \\
6.704 \mathrm{e}-003 \\
6.578 \mathrm{e}-003 \\
-6.451 \mathrm{e}-003 \\
6.325 \mathrm{e}-003 \\
6.199 \mathrm{e}-003 \\
6.073 \mathrm{e}-003 \\
5.947 \mathrm{e}-003 \\
5.821 \mathrm{e}-003
\end{array}
$$

(A) Radial diffuser
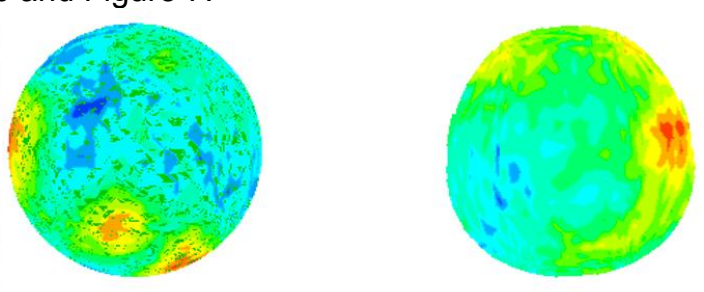

(B) Tangential diffuser

FIGURE 6 The pressure fluctuation intensity in the diffuser of volute

As shown in the Figure 6, in the diffuser of volute, whether in radial diffuser or tangential diffuser, under partload condition $\left(0.8 Q_{D E S}\right)$, the pressure fluctuation intensity of outer side is higher than that of inner side. The large gradient distribution of pressure fluctuation intensity were shown in the position close to the wall. Compare the pressure fluctuation intensity in radial diffuser with that in tangential diffuser, the distribution of pressure fluctuation intensity is more average and the gradient of pressure fluctuation is bigger.

$c p^{*}$

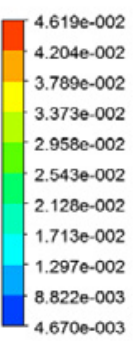

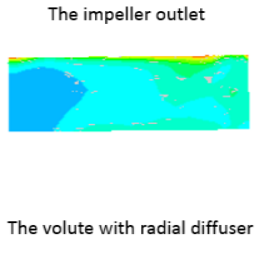

(A) Radial diffuser

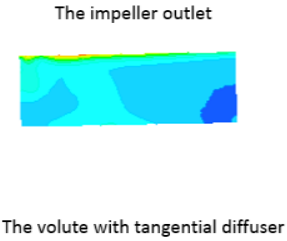

(B) Tangential diffuser
FIGURE 7 The pressure fluctuation intensity near the tongue of volute

As shown in the Figure 7, near the tongue of volute, whether in radial diffuser or in tangential diffuser, under partload condition $\left(0.8 Q_{D E S}\right)$, the large pressure fluctuation intensity were shown at the junction of the impeller outlet and the tongue inlet, which present that the rotor-stator interaction of impeller and tongue will cause large pressure fluctuation near the tongue. The pressure fluctuation intensity is smaller far away from the outlet of impeller. Compare the pressure fluctuation intensity in radial diffuser of volute with that in tangential diffuser of volute, the distribution of pressure fluctuation intensity is more average but the gradient of pressure fluctuation is smaller. The minimum value of pressure fluctuation intensity in tangential diffuser of volute is smaller than that in radial diffuser of volute.

\subsection{Time domain and frequency domain analysis}

Different diffuser types of volute have little effect on performance of pump from the Figure4, but can exert an influence on flow characteristic in pump and piping system. Especially under part-load condition, pressure fluctuation will be affected more obviously.

When the impeller blade passes by the volute tongue, a pressure fluctuation is initiated by the rotor-stator interaction of impeller and tongue. In the case of strong impeller-volute interaction, the pressure fluctuation become high enough to induce high vibration to pump components. So under partload condition, by using numerical analysis, in the two types of volute, the point $\mathrm{c} 1$ near the tongue and the point $\mathrm{c} 2$ in the outlet are set to obtain the time domain characteristics on pressure fluctuation, as shown in Figure8. 


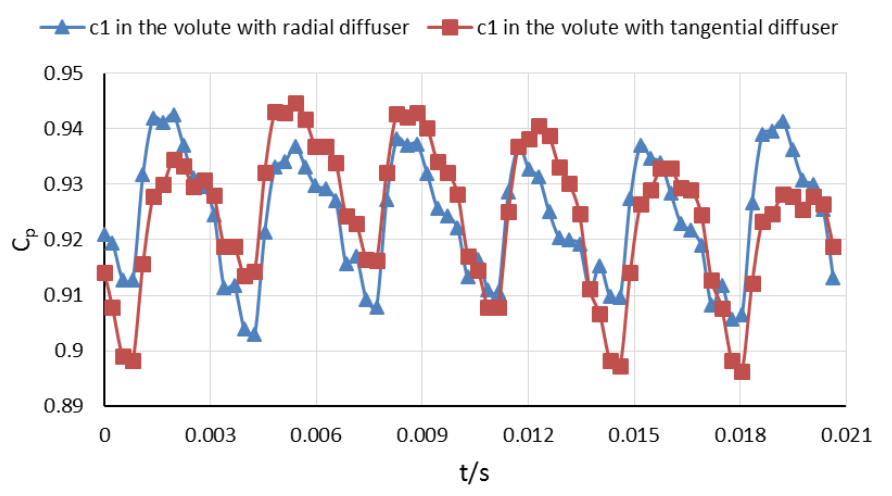

FIGURE 8 The time domain graph of pressure fluctuation near the tongue

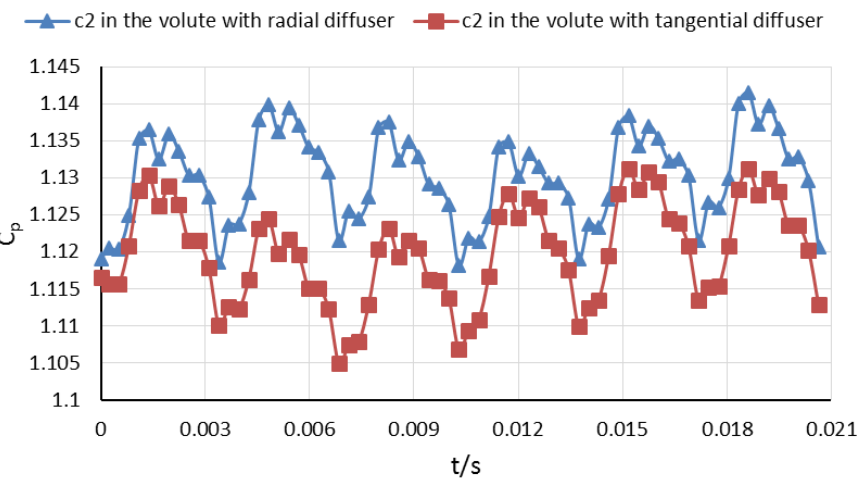

FIGURE 9 The time domain graph of pressure fluctuation in the diffuser of volute

As can be seen from the Figure 8 , under part-load condition $\left(0.8 Q_{D E S}\right)$ the change trend of pressure fluctuation near the tongue of volute with radial diffuser and the tongue of volute with tangential diffuser are basically same, and exhibit an evident periodicity properties. The peak value of pressure fluctuation is same near tongue of volute with two diffuser types.

As can be seen from the Figure 9, under part-load condition $\left(0.8 Q_{D E S}\right)$ the change trend of pressure fluctuation in the diffuser of volute with radial diffuser and the diffuser of volute with tangential diffuser are basically same, but the peak value of pressure fluctuation in the diffuser of volute with radial diffuser is greater than that of pressure fluctuation in the diffuser of volute with tangential diffuser. It also exhibit an evident periodicity properties. The pressure fluctuation amplitude different is small in two diffuser types of volute.

By comparison, the conclusion can be drawn, the periodic features in pressure fluctuation near its tongue are the same for two diffuser types of volute, but in the diffuser of the volute, the peak value of the pressure fluctuation in radial diffuser is greater than that in tangential diffuser.

By using fast fourier transform (FFT), under part-load condition $\left(0.8 Q_{D E S}\right)$ in the volute with two diffuser types, the pressure fluctuation frequency domain graph of the point $\mathrm{c} 1$ near the tongue and the point $\mathrm{c} 2$ in the diffuser are shown in Figure 10 and Figure 11. Where the blade passing frequency is $\mathrm{f}=\mathrm{n} / 60 \times \mathrm{Z}=290 \mathrm{~Hz}$

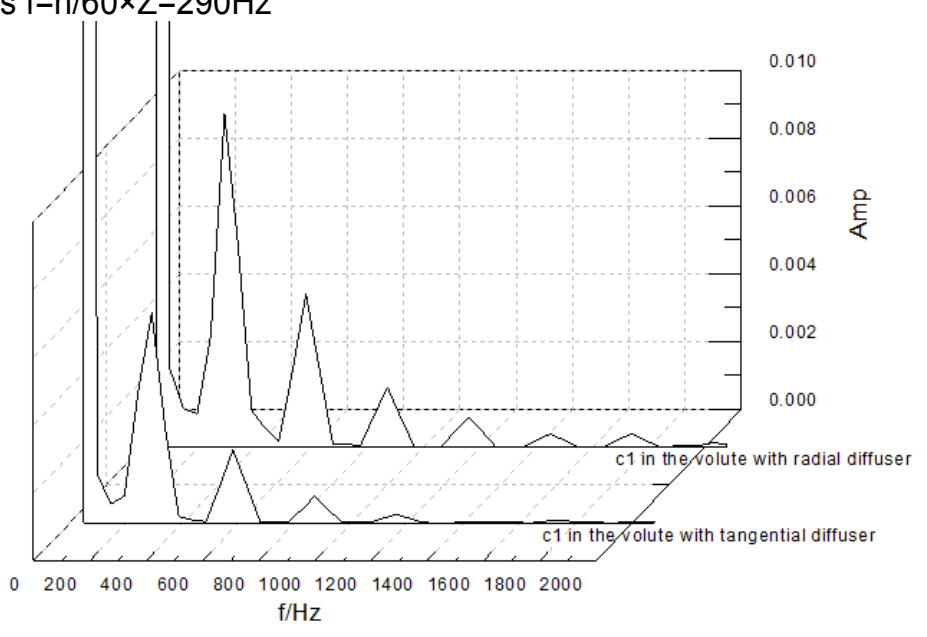

FIGURE 10 The frequency domain graph of point c1 near the tongue of volute with two diffuser types

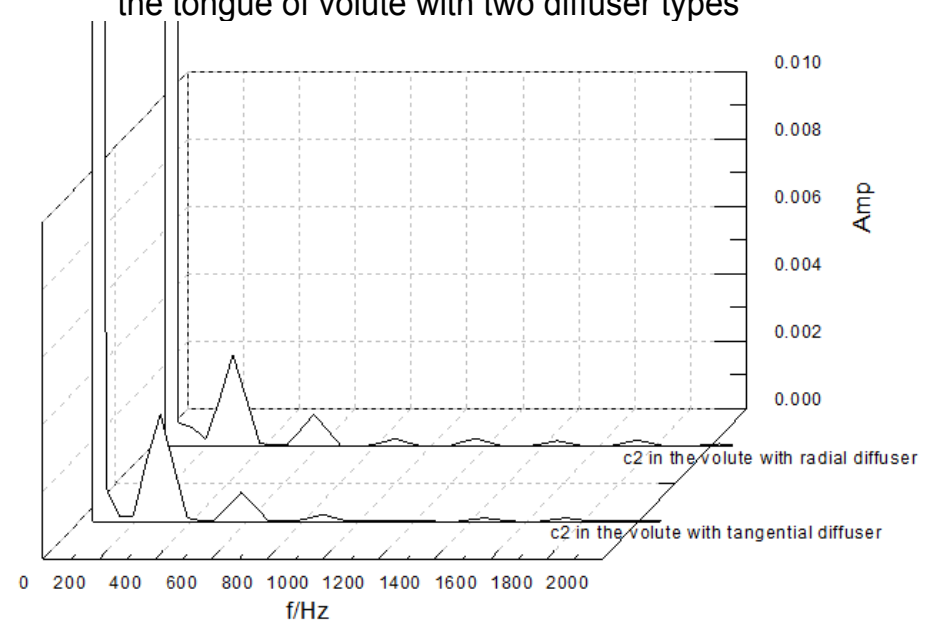

FIGURE 11 The frequency domain graph of point $\mathrm{c} 2$ in the diffuser of volute with two diffuser types

As shown in the Figure 10, near the tongue, under partload condition $\left(0.8 Q_{D E S}\right)$, the pressure fluctuation frequency based on blade pass frequency in two diffuser types of volute, and the pressure fluctuation amplitude in radial diffuser of volute is greater than that in tangential diffuser of volute.

As shown in the Figure 11, in the diffuser of volute, under part-load condition $\left(0.8 Q_{D E S}\right)$, the pressure fluctuation frequency also is based on blade pass frequency in two diffuser types, and the pressure fluctuation amplitude in tangential diffuser of volute is greater than that in radial diffuser of volute.

\section{CONCLUSION}

In this paper, by using the unsteady numerical simulation analysis of whole flow field in two diffuser types of 
volute, the volute with tangential diffuser and the volute with adial diffuser, the distribution of the pressure fluctuation intensity near the tongue of volute and that in the outlet of volute were obtained. Based on the analysis of pressure fluctuation intensity, the pressure fluctuation characteristics can be gained. Furthermore, by comparing the time domain and frequency domain graph on pressure fluctuation in two diffuser types of volute respectively, the following conclusions can be reached:

1 The different diffuser types of volute have little effect on performance of pump. However, under part-load condition, the pressure fluctuation will be affected more obviously.

2 In the outlet of volute, the pressure fluctuation intensity of outer side is higher than that of inner side. In radial diffuser, the distribution of pressure fluctuation intensity is more average and the gradient of pressure fluctuation is bigger.

3 Near the tongue, under part-load condition $\left(0.8 Q_{D E S}\right)$ the large pressure fluctuation intensity were shown at the junction of the impeller outlet and the tongue inlet. In radial diffuser of volute, the distribution of pressure fluctuation intensity is more average but the gradient of pressure fluctuation is smaller.

4 Under part-load condition $\left(0.8 Q_{D E S}\right)$, near the tongue, the change trend of pressure fluctuation are same for two diffuser types of volute. Furthermore, whether near the tongue or in the diffuser, the pressure fluctuation frequency is based on blade pass frequency for two diffuser types of volute.

The results can provide a useful reference for designing the diffuser of volute in centrifugal pump.

\section{ACKNOWLEDGMENTS}

This study was supported by Natural Science Foundation of Jiangsu Province Youth Fund (Grant No. BK20140554), National Natural Science Foundation of China (Grant No. 51409123), China Postdoctoral Science Foundation (Grant No. 2014M560402) Postdoctoral Science Foundation of Jiangsu Province (Grant No. 1401069B) and the Priority Academic Program Development of Jiangsu Higher Education Institutions (PAPD). The author make a grateful acknowledgement for the 4CPump research group.

\section{REFERENCES}

[1] Glc M, Usta N, Pancar Y. Effects of splitter blades on deep well pump performance [J]. Journal of Energy Resources Technology,2007,129:169 - 176.

[2] Kergourlay G, Younsi M, Bakir F, et al. Influence of splitter blades on the flow field of a centrifugal pump: Testanalysis comparison [J]. International Journal of Rotating Machinery,2007: 85024.
[3] Wang Wenquan, Zhang Lixiang, Yan, et al. Largeeddy simulation of turbulent flow considering in flow wakes in a franc is turbine blade passage [J]. Journal of Hydrodynamics, Ser. B, 2007, 19(2): 201 - 209.

[4] Germano M, Piomelll U, Mion P, et al. A dynamic sub grid - scale eddy viscosity model [J]. Physics of Fluid A, 1991, 3(7): 1760 - 1765.

[5] Longatte $\mathrm{F}$, Kueny $\mathrm{J} \mathrm{L}$ et al. Analysis of rotor-statorcircuit interactions in a centrifugal pump [C]. Proceedings of the 3rd ASME/JSME Joint Fluids Engineering Conference, 2009: 1039 - 1045.

[6] Kitano Majidi et al. Numerical study of unsteady flow in a centrifugal pump [J]. Journal of Turbomachinery, 2005, 127: $363-371$

[7] Guo Pengcheng et al. Numerical investigation and performance prediction on $3 \mathrm{~d}$ complex viscous flows in hydromachinery [D]. Xian: Xian University of Technology, 2009. (In Chinese with English abstract)

[8] Zhu Lei, et al. Numerical simulation on pressure fluctuations and radial hydraulic forces in a centrifugal pump with step-tongue [J]. Transactions of the Chinese Society for Agricultural Machinery, 2010, 41: 21 - 26. (in Chinese with English abstract)

[9] Chen Songshan, et al. Orthogonal experimental study on centrifugal pump with deviated splitter vanes [J]. Journal of Yangzhou University: Natural Science Edition, 2005 , 8(4): 45 - 48. ( in Chinese)

[10] Kitano Majidi et al. Numerical study of unsteady flow in a centrifugal pump [J]. Journal of Turbomachinery, 2005, 127: 363 - 371.

[11] Jianjun Feng et al. Application of different turbulence models in unsteady flow simulations of a radial diffuser pump [J]. Journal of Forsch Ingenieurwes: 123-133, 2010, 74 (3): 123-133.

[12] Kim, Jin Young et al. A numerical study of pump characteristics of a concrete volute pump with various types of volute [C]. The ASME-JSME-KSME 2011 Joint Fluid Engineering Conference.

[13] Ji Pei et al. Numerical investigation on periodic flow unsteadiness in a centrifugal pump with volute [M]. ASME 2013 Fluids Engineering Division Summer Meeting.

[14] Wang wen ji et al. Optimum hydraulic design for a radial diffuser pump using orthogonal experimental method based on CFD [M]. ASME 2014 Fluids Engineering Division. 